\title{
C-Type Lectin Domain Family 7 Member A
}

National Cancer Institute

\section{Source}

National Cancer Institute. C-Type Lectin Domain Family 7 Member A. NCI Thesaurus. Code C122763.

C-type lectin domain family 7 member A (247 aa, $\sim 28 \mathrm{kDa}$ ) is encoded by the human CLEC7A gene. This protein plays a role in the innate immune response against pathogenic bacteria and fungi. 